\title{
Posterior reversible encephalopathy syndrome in an untreated hypertensive patient after spinal surgery under general anesthesia -A case report-
}

\author{
Ji Hwan $\mathrm{Yi}^{1}$, Sang Hee $\mathrm{Ha}^{1}$, Yong Kook $\mathrm{Kim}^{1}$, and Eun Mi Choi ${ }^{2}$ \\ Department of Anesthesiology and Pain Medicine, ${ }^{1}$ Severance Hospital, Yonsei University College of Medicine, ${ }^{2}$ Kangnam Sacred \\ Heart Hospital, Hallym University College of Medicine, Seoul, Korea
}

Posterior reversible encephalopathy syndrome (PRES) is an unfamiliar term to anesthesiologists, and this is characterized by neurologic symptoms that include mental change, headache, seizure and visual disturbance and also abnormal neuroimaging finding. A 71-year-old female patient was operated on for posterior decompression and total laminectomy under general anesthesia for the spinal stenosis. After the operation, she developed generalized tonic-clonic seizure and a stuporous mentality in the recovery room. The magnetic resonance imaging (MRI) revealed swelling and increased signal intensity at the deep gray nuclei, cerebral cortex and cerebellum. After one week, she returned to an alert mentality and then she was diagnosed with PRES. She was discharged without any neurologic deficit on postoperative day 20. This report describes our experience with PRES after spinal surgery was performed under general anesthesia on a suspected untreated hypertensive patient. (Korean J Anesthesiol 2011; 60: 369-372)

Key Words: Brain edema, Hypertension, Posterior reversible encephalopathy syndrome.

In 1996, Hinchey et al. [1] reported 15 patients who had a reversible syndrome of headache, altered mental functioning, seizures and loss of vision associated with findings indicating predominantly posterior leukoencephalopathy on the imaging studies, and they named this reversible posterior leukoencephalopathy syndrome (RPLS). In 2000, Casey et al.
[2] performed a study on the neuroimaging findings of this syndrome and they proposed the term posterior reversible encephalopathy syndrome (PRES) to stress the common involvement of both the grey and white matter. In the field of anesthesiology, there are several reported cases of PRES during cesarean section or after insertion of epidural PCA in pregnant

Received: October 8, 2010. Revised: 1st, November 19, 2010; 2nd, November 22, 2010; 3rd, November 30, 2010. Accepted: December 2, 2010. Corresponding author: Eun Mi Choi, M.D., Department of Anesthesiology and Pain Medicine, Kangnam Sacred Heart Hospital, Hallym University College of Medicine, 948-1, Daerim 1-dong, Yeongdeungpo-gu, Seoul 150-950, Korea. Tel: 82-2-829-5230, Fax: 82-2-845-1571, E-mail: emchoi96@hallym.or.kr

(c) This is an open-access article distributed under the terms of the Creative Commons Attribution Non-Commercial License (http:// creativecommons.org/licenses/by-nc/3.0/), which permits unrestricted non-commercial use, distribution, and reproduction in any medium, provided the original work is properly cited. 
women with preeclampsia or eclampsia [3-5]. However, there has been no report about PRES in non-obstetric patients after general anesthesia. So, we report here on a case of PRES in a suspected untreated hypertensive patient after spinal surgery with the patient under general anesthesia.

\section{Case Report}

A 71-year-old female patient (height: $143 \mathrm{~cm}$ and weight: $48 \mathrm{~kg}$ ) was scheduled for posterior decompression and posterolateral fusion of L4-5-S1 under general anesthesia for spinal stenosis.

She never has been diagnosed with any disease, including hypertension. On the preoperative evaluation, the ECG showed right bundle branch block; cardiomegaly and pulmonary vascular congestion were noted on the chest plain radiography. The initial blood pressure (BP) was $140 / 80 \mathrm{mmHg}$. The cardiologist recommended evaluation for hypertension after surgery.

The BP after entering operating room was $175 / 87 \mathrm{mmHg}$ and the heart rate (HR) was 68 beats/min (bpm). Anesthesia was induced with $100 \mathrm{mg}$ of propofol, $50 \mathrm{mg}$ of rocuronium and 40 $\mathrm{g}$ of remifentanil. After intubation, the vital signs were 131/73 $\mathrm{mmHg}$ and $93 \mathrm{bpm}$. A 20-G catheter was placed on the left radial artery and a $16-\mathrm{G}$ intravenous catheter was inserted.

The surgical team moved the patient in the prone position for the surgical position, and after that, the BP was elevated to 175/87 $\mathrm{mmHg}$ and the HR was $68 \mathrm{bpm}$. During the surgery, the vital signs were maintained within the normal ranges. On completion of surgery, glycopyrrolate $0.2 \mathrm{mg}$ and pyridostigmine $10 \mathrm{mg}$ were administrated to reverse the residual muscle relaxation. The patient breathed spontaneously and opened her eyes to verbal commands. The endotracheal tube was removed after confirming that the patient was awake and the muscle function had been fully restored. The operation time was $3 \mathrm{~h} 15$ $\mathrm{min}$, and the duration of anesthesia was $3 \mathrm{~h} 50 \mathrm{~min}$.

In the recovery room, the initial $\mathrm{BP}$ was $128 / 73 \mathrm{mmHg}$, the HR was $91 \mathrm{bpm}$, the respiratory rate was 15 breaths/min and the pulse oximetry was $100 \%$. After 30 minutes, she responded to her name, but she was drowsy and answered incoherent words to verbal questions. After several minutes, she vomited two times and then generalized tonic-clonic seizure occurred. Thiopental $150 \mathrm{mg}$ was given to control the seizure and oxygen was also given. Five minutes later, she opened her eyes to verbal commands. Her BP was elevated, but the systolic BP remained at 140 to $165 \mathrm{mmHg}$, and the diastolic BP was 60 to $90 \mathrm{mmHg}$. The patient was evaluated with computed tomography (CT) and magnetic resonance imaging (MRI). The T2 weighted MRI showed swelling and an increased signal intensity at the deep gray nuclei, cerebral cortex and cerebellum (Fig. 1A). Slightly increased gyral enhancement was noted on the initial CT scan (Fig. 2A). She was transferred to the intensive care unit (ICU) for close monitoring and conservative management. In the ICU, $900 \mathrm{mg} /$ day of prophylactic sodium valproate was given intravenously to prevent the recurrence of seizure until postoperative day 13 . Her blood pressure is slightly above the normal range with a systolic $\mathrm{BP}$ of 130 to $160 \mathrm{mmHg}$ and a diastolic BP of 70 to $90 \mathrm{mmHg}$. Nicardipine were given by intermittent infusion to maintain the normal range of BP.

On postoperative day 4 , the patient's trachea was intubated due to a decreased mental status and possible aspiration pneumonia. On postoperative day 7, MRI was repeated and prominent subcortical lesions were mainly distributed in the posterior part of the brain (Fig. 1B). At this time, PRES was diagnosed according to the neuroimaging findings and the medical condition of her high blood pressure. On the 8th day, she opened her eye to speech and obeyed command. Her mentality recovered to an alert status.
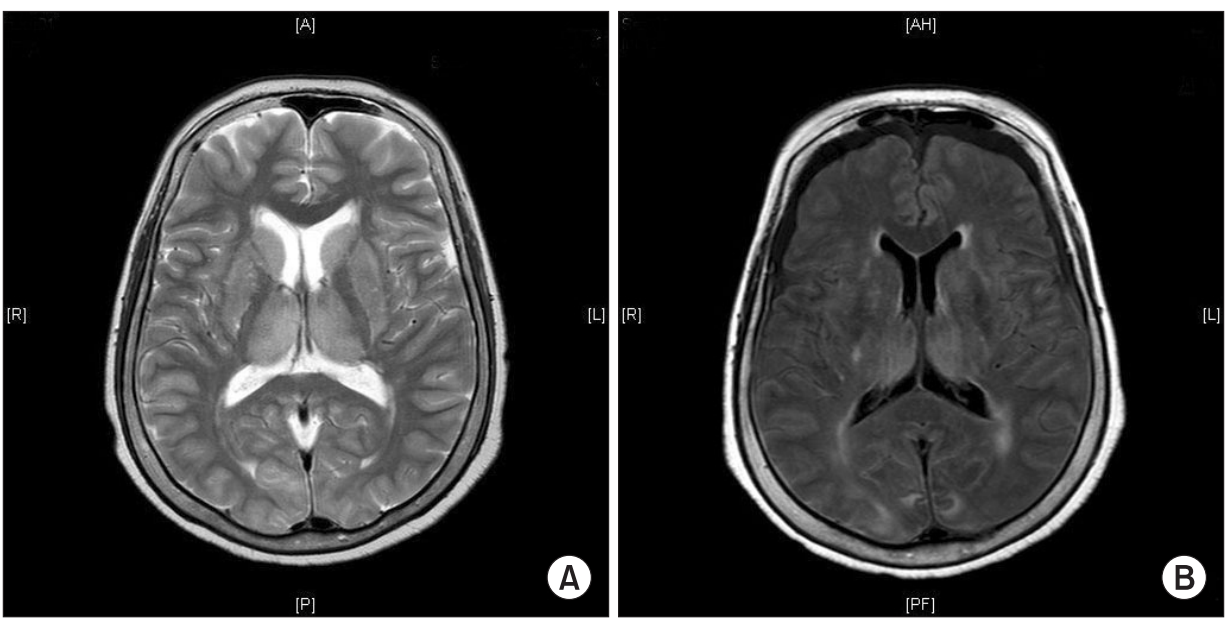

Fig. 1. Initial Magnetic resonance imaging (A) shows swelling and increased signal intensity at deep gray nuclei, cerebral cortex, and cerebellum, suggesting generalized injury on $\mathrm{T} 2$ weighted image. After 7 days, magnetic resonance imaging (B) shows decreased swelling of thalami, cerebellum and multifocal areas of cortex and subcortex in fluid attenuated inversion recovery (FLAIR) image. 

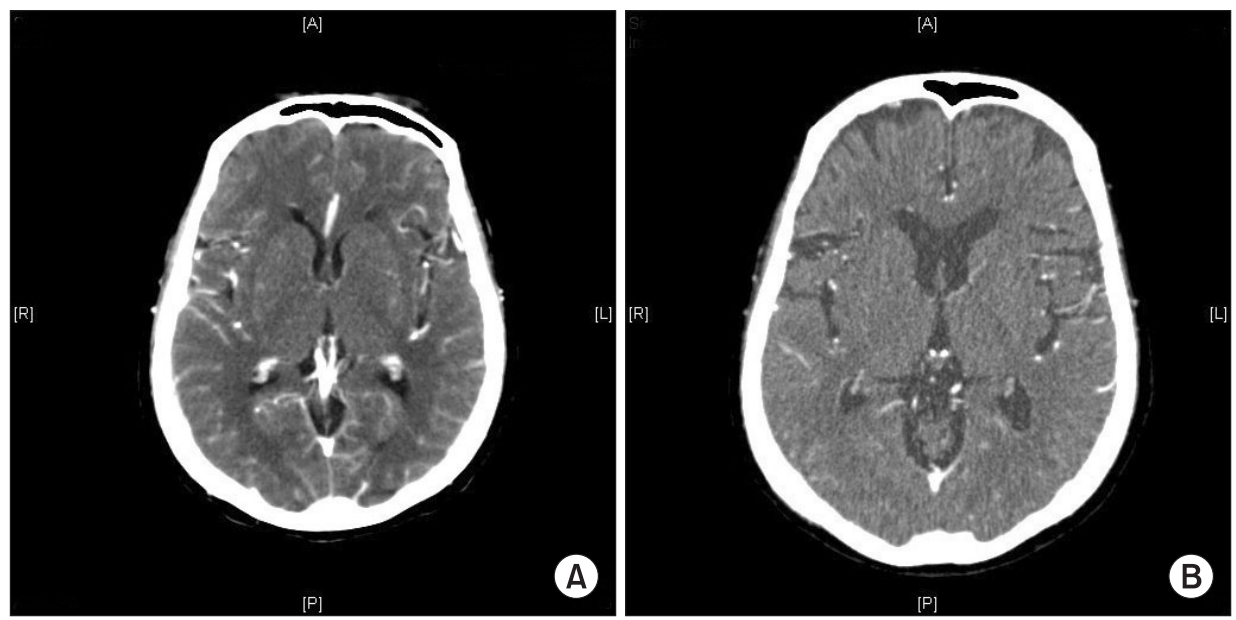

Fig. 2. Initial computed tomography (A) shows slightly increased gyral enhancement and 2 weeks later (B), shows no remarkable findings.

Extubation was done two weeks later. She was transferred to a general ward and oral antihypertensive medication with amlodipine $5 \mathrm{mg}$ was started. Brain CT was dome and it showed no remarkable findings (Fig. $2 \mathrm{~B}$ ). She was discharged with no residual neurologic symptoms on postoperative day 20 .

\section{Discussion}

PRES was first described in 1996 as a combination of neurological abnormalities and imaging findings that develop in patients with acute medical illness or in those who are being treated with immunosuppressive drugs [1]. The syndrome was initially recognized in association with severe hypertension, autoimmune disease, malignancy, immunosuppressive therapy or pregnancy $[4,5]$. High blood pressure was regarded as the major trigger factor in these patients.

Clinically, the most common symptom is generalized seizure associated with brain edema. According to Roth and Ferbert's report [6], generalized seizure occurred in $84 \%$ of the patients with PRES. Other frequent symptoms were visual changes (60\%), altered mental function (56\%), headache (52\%) and nausea and vomiting (28\%) [6]. There were 22 cases with elevated blood pressure, and the mean systolic blood pressure for all the patients was $170 \pm 37 \mathrm{mmHg}$. The symptoms resolved after about 7.5 days on average [6].

The neuroimaging abnormalities seen on CT and MRI typically show focal regions of symmetric white matter edema that most commonly affect the parietal and occipital lobes, and the posterior aspect of the frontal lobes might also be affected [7]. The posterior circulation supplied by the vertebro-basilar system has poor sympathetic innervation and so it is believed to be frequently involved [8].

The mechanism of PRES may be multifactorial and this remains controversial. Two opposing hypotheses are commonly cited: 1) The current more popular theory suggests that severe hypertension exceeds the limits of autoregulation, leading to breakthrough brain edema and 2) the earlier original theory suggests that hypertension leads to cerebral autoregulatory vasoconstriction, ischemia and subsequent brain edema [9]. The hypertension/hyperperfusion theory is primarily based on the blood pressure exceeding the autoregulation limits of the brain. However, the problems with this theory is that PRES is commonly seen without hypertension or with only a minor increase of blood pressure, as noted in the larger studies [1012]. Further investigations will be needed to more clearly understand the pathogenesis of PRES.

Reducing the blood pressure and seizure control are very important to treat and prevent aggravated cerebral edema. Magnesium sulfate has been the first line treatment for the patients who have eclampsia with PRES. Antihypertensive drugs, including hydralazine and labetalol, and antiseizure medication with close monitoring are recommended for the other patients with PRES [13].

In our case, the acute elevation of blood pressure such as occurred after position change was regarded as the major trigger factor for PRES. Owing to the brain edema and swelling, our patients showed generalized seizure and a stuporous mentality in the recovery room. We left much to be desired concerning the untreated preoperative hypertension and the delayed diagnosis.

As seen in this case, we should consider the possibility of PRES in patients with delayed emergence from general anesthesia, and especially for the patients with hypertension and/or eclampsia, or those who are receiving immunosuppressive therapy. Having a clinical suspicion is most important for the early recognition and diagnosis of PRES. So, we recommend early brain imaging evaluation for the suspected patients and strict blood pressure control because the latter is an important 
factor to prevent further brain damage.

\section{References}

1. Hinchey J, Chaves C, Appignani B, Breen J, Pao L, Wang A, et al. A reversible posterior leukoencephalopathy syndrome. N Engl J Med 1996; 334: 494-500.

2. Casey SO, Sampaio RC, Michel E, Truwit CL. Posterior reversible encephalopathy syndrome: utility of fluid-attenuated inversion recovery MR imaging in the detection of cortical and subcortical lesions. AJNR Am J Neuroradiol 2000; 21: 1199-206.

3. Hong JY, Jee YS, Lee IH, Shin JS, Choi HJ. Posterior reversible encephalopathy syndrome after cesarean section under spinal anesthesia. Korean J Anesthesiol 2007; 52: S86-90.

4. Torrillo TM, Bronster DJ, Beilin Y. Delayed diagnosis of posterior reversible encephalopathy syndrome (PRES) in a parturient with preeclampsia after inadvertent dural puncture. Int J Obstet Anesth 2007; 16: 171-4

5. Krishnamoorthy U, Sarkar PK, Nakhuda Y, Mullins PD. Posterior reversible encephalopathy syndrome (PRES) in pregnancy: a diagnostic challenge to obstetricians. J Obstet Gynaecol 2009; 29: 192-4.
6. Roth C, Ferbert A. Posterior reversible encephalopathy syndrome: long-term follow-up. J Neurol Neurosurg Psychiatry 2010; 81: 773-7.

7. Donmez FY, Basaran C, Kayahan Ulu EM, Yildirim M, Coskun M. MRI features of posterior reversible encephalopathy syndrome in 33 patients. J Neuroimaging 2010; 20: 22-8.

8. Schwartz RB. Hyperperfusion encephalopathies: hypertensive encephalopathy and related conditions. Neurologist 2002; 8: 22-34.

9. Bartynski WS. Posterior reversible encephalopathy syndrome, part 2: controversies surrounding pathophysiology of vasogenic edema. AJNR Am J Neuroradiol 2008; 29: 1043-9.

10. Sibai BM. Eclampsia. VI. Maternal-perinatal outcome in 254 consecutive cases. Am J Obstet Gynecol 1990; 163: 1049-54.

11. Reece DE, Frei-Lahr DA, Shepherd JD, Dorovini-Zis K, Gascoyne RD, Graeb DA, et al. Neurologic complications in allogeneic bone marrow transplant patients receiving cyclosporin. Bone Marrow Transplant 1991; 8: 393-401.

12. Shimono T, Miki Y, Toyoda H, Egawa H, Uemoto S, Tanaka K, et al. MR imaging with quantitative diffusion mapping of tacrolimusinduced neurotoxicity in organ transplant patients. Eur Radiol 2003; 13: 986-93.

13. Cunningham FG, Twickler D. Cerebral edema complicating eclampsia. Am J Obstet Gynecol 2000; 182: 94-100. 